\title{
Salbutamol in cardiogenic shock complicating acute myocardial infarction
}

\author{
J R DAWSON, P A POOLE-WILSON, G C SUTTON \\ From Hillingdon Hospital, Uxbridge, Middlesex, and Cardiothoracic Institute, 2 Beaumont Street, London
}

SUMMARY Intravenous salbutamol $(13 \mu \mathrm{g} / \mathrm{min})$ has been given to 31 patients with cardiogenic shock complicating acute myocardial infarction. Haemodynamic measurements were made in nine of these patients. Salbutamol increased cardiac index by 41 per cent from $1 \cdot 25 \pm 0.061 / \mathrm{min}$ per $\mathrm{m}^{2}$ to $1 \cdot 76 \pm$ $0.19 \mathrm{l} / \mathrm{min}$ per $\mathrm{m}^{2}$ and decreased systemic vascular resistance by 16 per cent from $26.2 \pm 1.9$ units to $21.9 \pm 2 \cdot 1$ units. Heart rate rose by 13 per cent from $95 \pm 4.5$ beats $/ \mathrm{min}$ to $106 \pm 6.0$ beats $/ \mathrm{min}$. Pulmonary artery end-diastolic pressure fell from $20.6 \pm 1.7 \mathrm{mmHg}$ to $16.9 \pm 1.9 \mathrm{mmHg}$. Of the 31 patients, eight survived to leave hospital $(27 \%)$. Five of the survivors had initial low heart rates and in these patients the clinical improvement was probably attributable to the positive chronotropic action of salbutamol. In the remaining three survivors clinical improvement was probably a result of salbutamol mediated afterload reduction. Salbutamol may be useful in the treatment of cardiogenic shock and pump failure complicating acute myocardial infarction.

Vasodilator drugs may improve cardiac performance in heart failure after acute myocardial infarction. ${ }^{1}$ Cardiac output is increased by a reduction in systemic vascular resistance (afterload) while myocardial oxygen demand falls as a result of reduced left ventricular wall tension. Salbutamol is a selective beta- 2 agonist first introduced for the treatment of bronchial asthma. ${ }^{2}$ Animal experiments suggest that its principal cardiovascular effect is a relaxation of vascular smooth muscle producing vasodilatation. ${ }^{3}{ }^{4}$ In man, though the exact mechanism is uncertain, beneficial haemodynamic effects with intravenous salbutamol have been described in patients with mitral valve disease, ${ }^{5}$ in low output states after cardiac surgery, ${ }^{6-8}$ and in congestive cardiomyopathy. ${ }^{\circ}$

Lal et al. ${ }^{10}$ treated 12 patients with cardiogenic shock after acute myocardial infarction with intravenous bolus injections of salbutamol ( 1 to $2 \mathrm{mg}$ ). Their report, which does not include haemodynamic data, describes clinical improvement in nine patients, six of whom survived to leave hospital.

We have treated 31 patients with cardiogenic shock after acute myocardial infarction with intravenous salbutamol, and describe the clinical outcome, as well as the haemodynamic responses in nine of them.

Received for publication 23 July 1979

\section{Patients}

Thirty-one patients with cardiogenic shock complicating acute myocardial infarction comprise the series. Cardiogenic shock was defined as systolic hypotension ( $<90 \mathrm{mmHg}$ ) associated with oliguria (urine output less than $30 \mathrm{ml} / \mathrm{h}$ ). All had clinical evidence of low cardiac output (peripheral vasoconstriction and disturbances of consciousness). Twenty-seven patients had radiological evidence of pulmonary oedema. In all patients intravenous frusemide ( 80 to $500 \mathrm{mg}$ ) had been ineffective in promoting a diuresis.

Nineteen patients had anterior and 12 had inferior infarcts; 14 had a previous history of angina or myocardial infarction. Sinus rhythm was present in 24 patients, three were in atrial fibrillation, and four were undergoing temporary pacing for complete heart block complicating the acute infarct.

All patients were given salbutamol by continuous intravenous infusion in a dose of $13 \mu \mathrm{g} / \mathrm{min}$. Haemodynamic measurements were made at the patient's bedside in the coronary care unit in nine patients (six men, three women; age range 52 to 68 , mean 59) eight of whom were in sinus rhythm, while one was being paced at a fixed ventricular rate of 90 for complete heart block. In the remaining 22 patients (17 men, five women; age range 52 to 72 , mean 59) the response to salbutamol was assessed 
by clinical observation together with measurements of heart rate, blood pressure, and urine output.

\section{Haemodynamic measurements}

A Swan-Ganz thermodilution catheter (CVI Model No. 600-017) was inserted percutaneously into the right subclavian vein and advanced to the pulmonary artery. Measurements were made of right atrial, right ventricular, pulmonary artery, and wedge pressures. The sternal angle was used as the zero reference point. In all patients pulmonary artery end-diastolic pressure (PAEDP) was found to correlate closely with wedge pressure and in order to avoid frequent catheter manipulations PAEDP was used in most subsequent recordings as an indirect assessment of left ventricular filling pressure. Cardiac output was measured by the thermodilution technique ${ }^{11}$ using a cardiac output computer (CVI Model No. 600). The injectate was $10 \mathrm{ml}$ normal saline at room temperature. Each value for cardiac output was derived from the average of at least three estimations. Systemic arterial pressure was recorded with an Infrasonde electronic sphygmomanometer (Model No. 3000). Mean arterial pressure was calculated as the diastolic pressure plus a third of the pulse pressure. Heart rate was obtained from an electrocardiogram recorded simultaneously with each measurement of intracardiac pressure and was averaged over 20 beats. Intravenous salbutamol $(10 \mathrm{mg}$ in $500 \mathrm{ml}$, $5 \%$ dextrose) was given in a dose of $13 \mu \mathrm{g} / \mathrm{min}$, the infusion rate being controlled by a Tekmar 51 pump. The intracardiac pressures, cardiac output, heart rate, and arterial pressure were recorded at the beginning and end of a 20-minute control period and then at 10,20 , and 40 minutes after the start of the salbutamol infusion. Cardiac index, stroke index, and systemic vascular resistance

mean arterial pressure - mean right atrial pressure

cardiac output

were calculated. The results recorded are at the end of the control period and at $\mathbf{4 0}$ minutes from the start of salbutamol infusion and values are compared using Student's paired t test.

\section{Results}

In nine patients who had haemodynamic measurements, the changes induced by salbutamol are shown in the Figure. Cardiac index rose in all patients from $1.25 \pm 0.06 \mathrm{l} / \mathrm{min}$ per $\mathrm{m}^{2}$ to $1.76 \pm$ $0.191 / \mathrm{min}$ per $\mathrm{m}^{2}(41 \%, \mathrm{p}<0.002)$. Stroke index increased by an average of 28 per cent from $13.2 \pm$ $0.74 \mathrm{ml} /$ beats per $\mathrm{m}^{2}$ to $16.9 \pm 1.4 \mathrm{ml} /$ beat per $\mathrm{m}^{2}$ $(p<0.005)$. Heart rate rose by an average of 13 per cent from $95 \pm 5$ beats/min to $107 \pm 6 \cdot 6$ beats/ min $(p<0.05)$. Systemic vascular resistance fell from $26.2 \pm 1.9$ units to $21.9 \pm 2.1$ units $(16 \%$, $\mathrm{p}<0.02$ ).

Pulmonary artery end-diastolic pressure fell from $20.6 \pm 1.7 \mathrm{mmHg}$ to $16.9 \pm 1.9 \mathrm{mmHg}$ after salbutamol $(18 \%, \mathrm{p}<0.05)$. There was a small, though insignificant, increase in mean arterial pressure from $64 \cdot 8 \pm 4 \cdot 1 \mathrm{mmHg}$ to $70 \cdot 3 \pm 4.7$ mmHg. After completion of the haemodynamic measurements, all these patients continued treatment with intravenous salbutamol. Two patients (one with an anterior and one with an inferior infarct) survived to leave hospital. In this group there were no appreciable differences in the initial haemodynamic indices between the two survivors and the seven non-survivors. In one patient, a nonsurvivor, the salbutamol infusion had to be stopped because of the development of supraventricular tachycardia; this was the only complication in the series.

In the 22 patients who did not have haemodynamic measurements there were similar changes in heart rate and mean arterial pressure. Excluding the three patients who were being paced for complete heart block, the heart rate rose from $88 \pm 5.8$ beats/min to $101 \pm 4.9$ beats/min (average $15 \%$, $\mathrm{p}<0.001)$. Mean arterial pressure did not change significantly (mean $71 \pm 3 \mathrm{mmHg}$ before, and mean $74 \pm 3 \mathrm{mmHg}$ ) (average $4 \%$ ). Six patients from this group (four with inferior and two with anterior infarcts) survived to leave hospital. Initial heart rate ( $63 \pm 2.5$ beats/min) was significantly lower in the survivors than in the non-survivors $(99 \pm 9 \cdot 1$ beats $/ \mathrm{min})(\mathrm{p}<0.005)$.

Urine output was measured in all patients and increased from a mean of $9 \pm 1.7 \mathrm{ml} / \mathrm{h}$ to a mean of $72 \pm 22.6 \mathrm{ml} / \mathrm{h}$ after salbutamol $(\mathrm{p}<0.01)$.

\section{Discussion}

Clinical evidence of cardiogenic shock with pump failure was present in all patients with systemic hypotension, peripheral vasoconstriction, oliguria, and in most cases pulmonary oedema. In nine patients in whom haemodynamic measurements were made, the extremely low initial cardiac outputs further emphasise the severity of pump failure present in these patients. Salbutamol significantly increased cardiac index, stroke index, and heart rate while reducing systemic vascular resistance and left ventricular filling pressure. The percentage rises in cardiac index $(41 \%)$ and fall in systemic 
vascular resistance $(16 \%)$ are similar to those changes noted by ourselves, ${ }^{12}$ and by Sharma and Goodwin $^{2}$ in patients with chronic heart failure treated with intravenous salbutamol. The increase in heart rate $(13 \%)$ is similar to that found by Gibson and Coltart ${ }^{5}$ in patients with mitral valve disease and by Poole-Wilson et al. ${ }^{8}$ in patients after open heart surgery but was a less striking feature of our patients with chronic heart failure.

The exact mode of action of salbutamol on the human cardiovascular system is not clearly established. Cullum et al. ${ }^{3}$ working with animals, showed that salbutamol has $1 / 10$ the activity of isoprenaline on vascular smooth muscle but only $1 / 2000$ its activity in increasing heart muscle tension. This implies that the increased cardiac output noted with salbutamol is principally a result of vasodilatation secondary to beta-adrenergic stimulation of vascular smooth muscle rather than a direct cardiac effect. This finding, that salbutamol has a negligible effect on heart muscle beta-adrenergic receptors, was confirmed by Nayler ${ }^{4}$ working with isolated human heart muscle preparations. In addition,
Nayler showed that in dog preparations there was evidence of salbutamol mediated direct coronary artery dilatation which is not dependent upon an increase in myocardial oxygen demand. The results of these in vitro experiments tend to conform with the findings in the majority of reports on patients with heart disease, ${ }^{57812}$ though Sharma and Goodwin, ${ }^{9}$ whose patients had congestive cardiomyopathy, concluded that salbutamol induced increases in cardiac output are a result of positive inotropic stimulation.

We believe that the increased cardiac output observed in our patients was probably a result of vasodilatation rather than a positive inotropic effect. In preparations of isolated rabbit papillary muscle the minimum concentration of salbutamol required to produce a positive inotropic effect is $0.09 \mathrm{mg} / \mathrm{l}^{12} 10$ times the estimated serum concentration of salbutamol in man that would be achieved by an infusion rate of $13 \mu \mathrm{g} / \mathrm{min}$.

An increase in heart rate was observed in the majority of our patients and appears to have been beneficial in some, though excessive increases in
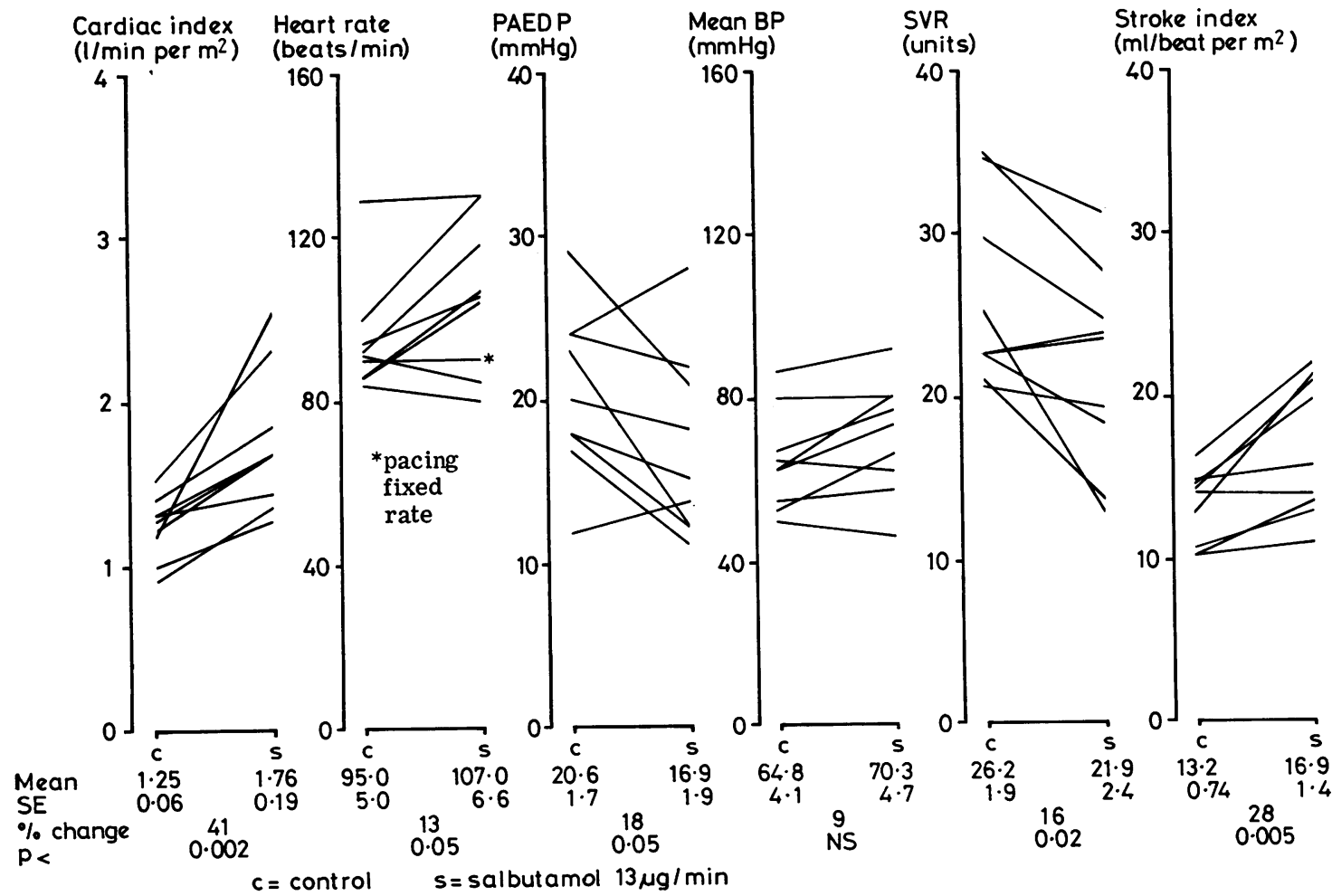

Fig. The changes in cardiac index, heart rate, pulmonary artery end-diastolic pressure (PAEDP), mean blood pressure (BP), systemic vascular resistance (SVR), and stroke index with salbutamol. 
heart rate may be detrimental to an already ischaemic myocardium by increasing myocardial oxygen consumption..$^{13}$ The mechanism of the increase in heart rate was not determined.

In this study, eight patients $(27 \%)$ survived to leave hospital. This survival rate is similar to previously reported rates in patients with cardiogenic shock complicating myocardial infarction. ${ }^{14}$ In five of the survivors (four inferior and one anterior infarct) initial heart rate was inappropriately low. The chronotropic action of salbutamol may have been responsible for the clinical improvement observed in these patients. In the remaining three survivors (two anterior and one inferior infarct) initial heart rate was high (mean 92 beats/min), and in the two patients for whom haemodynamic data are available the initial haemodynamic indices in survivors were the same as in non-survivors. In these patients improved cardiac performance was probably mediated by salbutamol induced afterload reduction. Though a non-survivor, one patient who had measured haemodynamic responses was being paced for complete heart block. This patient had similar increases in cardiac output and stroke index, and similar falls in systemic vascular resistance and left ventricular filling pressure as the remaining eight patients, though heart rate of course remained constant.

Vasodilators are now widely advocated in the treatment of pump failure after acute myocardial infarction though survival rates are low. Sodium nitroprusside, ${ }^{15}$ phentolamine, ${ }^{16}$ glyceryl trinitrate, ${ }^{17}$ and isosorbide dinitrate ${ }^{18}$ have all been shown to have beneficial haemodynamic effects. Our findings suggest that, though survival was disappointingly low in spite of treatment, salbutamol is a valid alternative drug in the management of pump failure and cardiogenic shock complicating acute myocardial infarction.

We thank Allen \& Hanbury Ltd for supplying the intravenous salbutamol.

\section{References}

${ }^{1}$ Chatterjee K, Parmley WW. Vasodilator treatment for acute and chronic heart failure. Br Heart $\mathcal{F}$ 1977; 39: 706-20.

${ }^{2}$ Choo-kang YFJ, Simpson WT, Grant IWB. Controlled comparison of the bronchodilator effects of three $\beta$ adrenergic stimulant drugs administered by inhalation to patients with asthma. $B r$ Med f 1969; 2: 287-9.
${ }^{3}$ Cullum VA, Farmer JB, Jack D, Levy GP. Salbutamol: a new selective 3 adrenoreceptive stimulant. $\mathrm{Br} \mathcal{F}$ Pharmacol 1969; 35: 141-51.

${ }^{4}$ Nayler WG. Some observations on the pharmacological effects of salbutamol with particular reference to the cardiovascular system. Postgrad Med f 1971; 47, suppl: 16-21.

${ }^{5}$ Gibson DG, Coltart DJ. Haemodynamic effects of intravenous salbutamol in patients with mitral valve disease; comparison with isoprenaline and atropine. Postgrad Med f 1970; 47, suppl (March): 40-4.

'Yacoub MH, Boyland G. Cardiovascular effects of intravenous salbutamol after open heart operations. Lancet 1973; 1: 1260-1.

${ }^{2}$ Wyse SD, Gibson DG, Braithwaite MA. Haemodynamic effects of salbutamol in patients needing circulatory support after open heart surgery. $\mathrm{Br} M e d \mathcal{F}$ 1974; 3: 502-3.

8Poole-Wilson PA, Lewis G, Angerpointer T, Malcolm $\mathrm{AD}$, William BT. Haemodynamic effects of salbutamol and nitroprusside after cardiac surgery. $\mathrm{Br}$ Heart $\mathcal{f}$ 1977; 39: 721-5.

${ }^{9}$ Sharma B, Goodwin JF. Beneficial effect of salbutamol on cardiac function in severe congestive cardiomyopathy: effect on systolic and diastolic function of the left ventricle. Circulation 1978; 58: 449-60.

${ }_{10}$ Lal S, Savidge RS, Davies DM, Ali MM, Soni V. Intravenous salbutamol and cardiogenic shock. Lancet 1972; 1: 853-4.

${ }^{11 G a n z ~ W, ~ S w a n ~ H J C . ~ M e a s u r e m e n t ~ o f ~ b l o o d ~ f l o w ~ b y ~}$ thermodilution. Am $\mathcal{F}$ Cardiol 1972; 29: 241-6.

12Bourdillon PDV, Dawson JR, Foale RA, Timmis AD, Poole-Wilson PA, Sutton GC. Salbutamol in treatment of heart failure. Br Heart $\mathcal{f} 1980$; 43: 206-10.

${ }^{13}$ Braunwald E. Control of myocardial oxygen consumption; physiologic and clinical considerations. $\mathrm{Am} \mathcal{F}$ Cardiol 1971; 27: 416-32.

14Resnekov L. Circulatory assistance for the failing heart. Br Heart f 1973; 35: 1265-70.

15 Franciosa JA, Guiha NH, Limas CJ, Rodrigneva E, Cohn JN. Improved left ventricular function during nitroprusside infusion in acute myocardial infarction. Lancet 1972; 1: 650-4.

${ }_{16}$ Kelly DT, Delgado CE, Taylor DR, Pitt V, Ross RS. Use of phentolamine in acute myocardial infarction associated with hypertension and left ventricular failure. Circulation 1973; 47: 729-35.

17Flaherty JT, Reid PR, Kelly DT, Taylor DR, Weisfeldt ML, Pitt B. Intravenous nitroglycerine in acute myocardial infarction. Circulation 1975; 51: 132-9.

18Baxter RH, Tait CM, McGuinness JB. Vasodilator therapy in acute myocardial infarction. Use of sublingual isosorbide dinitrate. $\mathrm{Br}$ Heart $\mathcal{f} 1977$; 39: 1067-70.

Requests for reprints to Dr G C Sutton, Hillingdon Hospital, Uxbridge, Middlesex UB8 3NN. 